\title{
Biocompatible Block Copolymers Composed of Polydimethylsiloxane and Poly[(2-methacryloyloxy)ethyl phosphorylcholine] Segments
}

\author{
Kazuo Sugiyama, ${ }^{\dagger}$ Kohei Shiraishi, Kiyotaka OKada, ${ }^{*}$ \\ and Osamu MATSUO*
}

Department of Chemistry \& Environmental Technology, Faculty of Engineering, Kinki University, 1 Takaya-Umenobe, Higashihiroshima, Hiroshima 739-2116, Japan * Department of Physiology, Kinki University School of Medicine, Osakasayama 589-0014, Japan

(Received July 30, 1998)

\begin{abstract}
KEY WORDS Poly(dimethylsiloxane) / Poly[2-(methacryloyloxy) ethyl phosphorylcholine] / Block Copolymer / Microphase Separation / Platelet Adhesion /
\end{abstract}

Some graft and block copolymers containing the polydimethylsiloxane (PDMS) segment have been synthesized so far, for the improvement of mechanical property and the biocompatibility of silicone rubber as a useful biomedical material. ${ }^{1-4}$ On the other hand, there is no doubt that incorporation of the polar head group of phosphorylcholine into a polymer is useful for providing materials with biocompatibility. In addition to the homopolymer (PMPC) ${ }^{5}$ of 2-(methacryloyloxy)ethyl phosphorylcholine (MPC), copolymers consisting of MPC and alkyl methacrylates, for instance, show reduced protein adsorption from human plasma and reduced activation of platelets. ${ }^{6-10}$ On this note a novel PDMS type of block copolymers (PMPC- $b$-PDMS) composed of PMPC and PDMS segments was prepared by radical polymerization of MPC initiated with a PDMS type of azo-initiator. ${ }^{11,12}$ The biocompatibility of PMPC- $b$-PDMS was evaluated by the adsorption of protein and the adhesion of human platelets.

\section{EXPERIMENTAL}

\section{Reagents}

The macroazo-initiator (VPS: $M_{n}=3 \times 10^{4}-4 \times 10^{4}$ ) was kindly supplied by Wako Pure Chemicals and used without further purification. MPC was synthesized as described in a previous paper. ${ }^{9}$ Crystallized and lypophilized bovine serum albumin (Alb, Sigma Chemicals), human serum $\gamma$-globulin (Glo, Wako Pure Chemicals) and bovine serum fibrinogen (Fib, Sigma Chemicals) were used as obtained.

\section{Polymerization}

A series of PMPC- $b$-PDMS-I-VI with different molar ratios of PMPC segment to PDMS segment $(p: q)$ was prepared by radical polymerization of MPC initiated with VPS in a mixed solvent of $\mathrm{CHCl}_{3}$ and ethanol $(70: 30$ vol $\%$ ) at $60^{\circ} \mathrm{C}$ for $20 \mathrm{~h}$, varying the molar ratio of MPC to the dimethylsiloxane (DMS) unit in VPS from $0.05: 0.95$ to $0.50: 0.50$ (Scheme 1 and Table I). PMPC- $b$-PDMS was purified by reprecipitation from the ethanol-diethylether system twice.

\footnotetext{
† To whom correspondence should be addressed.
}

\section{Protein Adsorption Procedure}

The amount of adsorbed protein was measured by the same method described in a previous paper. ${ }^{13}$ The column $(20 \mathrm{~mm} \phi, 300 \mathrm{~mm}$ in height) used was filled with $83.34 \mathrm{~g}\left(1.0 \mathrm{~m}^{2}\right)$ of glass beads surface-covered with PMPC- $b$-PDMS, which were prepared by immersing the glass beads $\left(0.20 \mathrm{~mm} \phi, 1.0 \mathrm{~m}^{2}\right.$ of total surface area) in the $1 \mathrm{wt} \%$ ethanol solution of PMPC- $b$-PDMS and drying them in a vacuum at room temperature for $24 \mathrm{~h}$. The amount of protein adsorbed on the glass beads was calculated from the content of the free protein remaining in the phosphate buffer solution (PBS, pH 5.6 for Alb; pH 6.2 for Glo; pH 5.7 for Fib) by measuring the absorbance at $750 \mathrm{~nm}$ of protein, according to the Lowry method. ${ }^{14}$

\section{Platelet Adhesion}

Platelet-rich plasma (PRP) and platelet-poor plasma (PPP) were collected from healthy humans according to the method described in literature. ${ }^{10}$ The PRP was diluted with PPP to control the number of platelets $\left(12.7 \times 10^{7}\right.$ cells $\mathrm{cm}^{-3}$ ). The poly(ethylene terephthalate) (PET) film coated with PMPC- $b$-PDMS-V (see Table I) was placed on the bottom of the well (Corning 24 mutiwells, diameter: $15 \mathrm{~mm}$ ) and put in contact with $0.6 \mathrm{~mL}$ of PRP at room temperature for $3 \mathrm{~h}$. The PET film was rinsed with $1 \mathrm{~mL}$ of phosphate-buffered solution (PBS, pH 7.4) twice to remove the unadhered platelets, and then immersed in PBS containing the $2 \mathrm{wt} \%$ of glutaraldehyde to fix the adhered platelets. The film was then freeze-dried and coated with gold using a JEOL JFC-1100E ion sputter apparatus.

\section{Other Measurements}

${ }^{1} \mathrm{H}$ NMR spectra were recorded on a JEOL EX 400 spectrometer. Scanning electron microscope (SEM) and transmission electron microscope (TEM) images were taken by means of JEOL JSM-82 and JEOL 2000 FX, respectively. The surface of the vacuum-dried and freeze-dried films, which were prepared by casting the $3 \%$ ethanol solution of PMPC- $b$-PDMS on the PET film, was analyzed by means of X-ray photoelectron spectroscopy (XPS, Shimadzu ESCA 750) using $\mathrm{Mg}-K_{\alpha}$ in a vacuum of less than $6.6 \times 10^{-5} \mathrm{~Pa}$. The static contact 


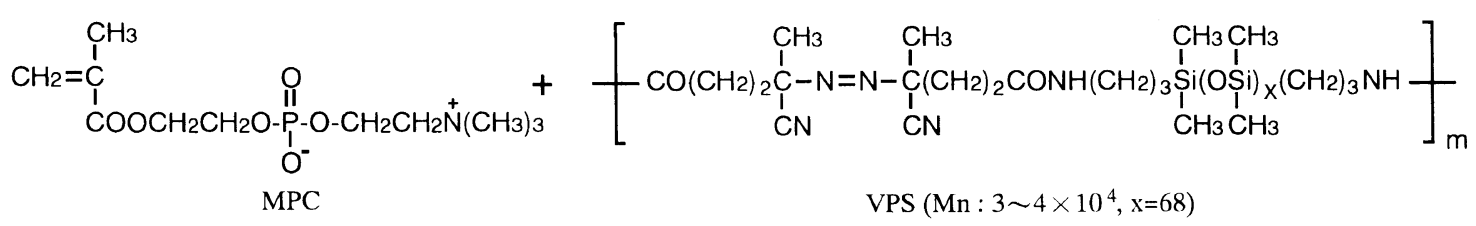

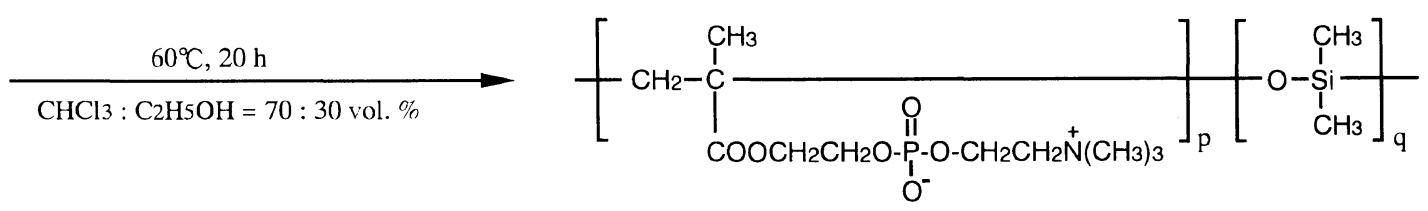

PMPC-b-PDMS

Scheme 1. Preparation of PMPC- $b$-PDMS.

Table I. Preparation and characterization of PMPC- $b-$ PDMS $^{\text {a }}$

\begin{tabular}{|c|c|c|c|c|c|}
\hline PDMS- $b$-PMPC & $\begin{array}{c}\text { MPC : DMS } \\
\text { (Molar ratio in feed) }\end{array}$ & $\frac{\text { Yield }}{\%}$ & $\frac{[\eta]^{\mathrm{b}}}{\mathrm{dLg}^{-1}}$ & $\begin{array}{c}p: q^{\mathbf{c}} \\
\text { (Molar ratio in } \\
\text { block copolymer) }\end{array}$ & Property \\
\hline I & $0.05: 0.95$ & 90.3 & $0.12^{\mathrm{d}}$ & $0.03: 0.97^{\mathrm{e}}$ & Transparent rubbery \\
\hline II & $0.08: 0.92$ & 89.7 & $0.13^{\mathrm{d}}$ & $0.07: 0.93^{\mathrm{e}}$ & White rubbery \\
\hline III & $0.17: 0.83$ & 90.6 & 0.15 & $0.15: 0.85$ & White rubbery \\
\hline IV & $0.23: 0.76$ & 90.4 & 0.15 & $0.20: 0.80$ & White powdery \\
\hline $\mathrm{V}$ & $0.27: 0.73$ & 88.0 & 0.17 & $0.25: 0.75$ & White powdery \\
\hline VI & $0.50: 0.50$ & 81.3 & 0.22 & $0.48: 0.52$ & White powdery \\
\hline
\end{tabular}

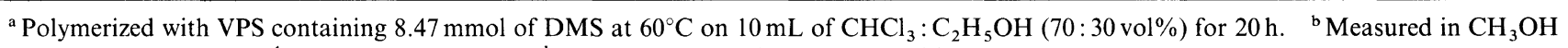
at $25^{\circ} \mathrm{C} .{ }^{\mathrm{c}}$ Calculated from ${ }^{1} \mathrm{H}$ NMR in $\mathrm{CD}_{3} \mathrm{OD}$. ${ }^{\mathrm{d}}$ Measured in $\mathrm{CHCl}_{3}$. ${ }^{\mathrm{e}}$ Measured in $\mathrm{CDCl}_{3}$.

angles $(\theta)$ of water were measured at an ambient temperature using the sessile drop method with an Erma contact angle meter, Model G-1, using the PET film covered with PMPC- $b$-PDMS as described above. UV-Vis measurements were performed with a Shimadzu UV-160A spectrophotometer.

\section{RESULTS AND DISCUSSION}

\section{Synthesis and Characterization of PMPC-b-PDMS}

A series of block copolymers, PMPC- $b$-PDMS-I-VI, was obtained at a high yield, as shown in Scheme 1 and Table I. The molar ratio of the PMPC segment to the PDMS segment $(p: q)$ in block copolymers was determined from the comparison of the peak area for $\mathrm{COOCH}_{2} \mathrm{CH}_{2} \quad(3.80 \mathrm{ppm})$ of PMPC with that for $\left(\mathrm{CH}_{3}\right)_{2} \mathrm{SiO}(0.15 \mathrm{ppm})$ of PDMS by ${ }^{1} \mathrm{H}$ NMR spectroscopy. The $p: q$ in PMPC- $b$-PDMS agrees closely with the molar ratio of MPC to DMS in feed. The series of PMPC- $b$-PDMS varied in appearance from rubbery to white powdery, depending on the amount of the PMPC segment ( $p$-value). The solubility of PMPC- $b$-PDMS was also changed by the $p$-value as follows: PMPC- $b$-PDMS with $p \leqq 0.07$ was soluble in various organic solvents such as $\mathrm{CHCl}_{3}$ and benzene, whereas PMPC- $b$-PDMS with $p \geqq 0.15$ was soluble in ethanol and insoluble but swelled up in water. The surface of the freeze-dried and vacuum-dried PMPC- $b$-PDMS-V film (see Table I) was analyzed by XPS. The signals for silicon $\left(\mathrm{Si}_{2 p}\right)$ at a binding energy $(\mathrm{EB})$ of $102 \mathrm{eV}$, phosphorus $\left(\mathrm{P}_{2 \mathrm{p}}\right)$ at an $\mathrm{EB}$ of $133 \mathrm{eV}$, and nitrogen $\left(\mathrm{N}_{1 \mathrm{~s}}\right)$ at an $\mathrm{EB}$ of $400 \mathrm{eV}$
Table II. XPS analysis data for PMPC- $b$-PDMS-V

\begin{tabular}{lccc}
\hline PMPC- $b$-PDMS-V & $\mathrm{N} / \mathrm{C} \times 10^{3}$ & $\mathrm{P} / \mathrm{C} \times 10^{3}$ & $\mathrm{Si} / \mathrm{C} \times 10^{3}$ \\
\hline XPS vacuum-dried & 13 & 3 & 327 \\
XPS freeze-dried & 35 & 23 & 273 \\
\hline
\end{tabular}

were assigned to the DMS unit in the PDMS segment and the phosphorylcholine group in the MPC moiety. It was found from the comparison of the freeze-dried surfaces with the vacuum-dried ones that the atom ratios for nitrogen and phosphorus to carbon were found to increase from $\mathrm{N} / \mathrm{C}=13 \times 10^{-3}$ to $\mathrm{N} / \mathrm{C}=35 \times 10^{-3}$ and from $\mathrm{P} / \mathrm{C}=3 \times 10^{-3}$ to $\mathrm{P} / \mathrm{C}=23 \times 10^{-3}$, respectively, as shown in Table II. Taking into account the fact that the hydrophilic segment tends to reorganize to minimize the energy depending on the surface condition in the copolymer consists of two kinds of segments with different surface free energy, ${ }^{2,15}$ a preferential existence would be expected for the PMPC segment of PMPC- $b$ PDMS at the water-contacting interface. ${ }^{9}$ The silicone rubber sheds water well, while PMPC- $b$-PDMS shows an improved wettability due to the PMPC segment. The static contact angles $(\theta)$ were measured in order to evaluate the wettability of PMPC- $b$-PDMS. Figure 1 shows the effect of the amount of PMPC segment $(p)$ on the contact angle of the PMPC- $b$-PDMS. The static contact angles of PMPC- $b$-PDMS dropped from $\theta=103^{\circ}$ to $\theta=25^{\circ}$ when increasing the amount of the MPC segment. This means that PMPC- $b$-PDMS can form a hydrogel structure in water and exhibit the biocompat- 
ibility mentioned below. It is also known that the kind of block copolymers such as poly(2-hydroxyethyl metacrylate)-polystyrene-poly(2-hydroxyethyl metacrylate) triblock copolymer ${ }^{16}$ and segmented polyetherurethaneurea $^{17}$ have a microphase separated structure and exhibit an excellent antithrombogenic property. PMPC$b$-PDMS-V (see Table I) was then morphologically analyzed with a TEM in order to confirm such a structure after staining the sliced surface of the sample with $\mathrm{RuO}_{4}$ vapor. PMPC- $b$-PDMS-V was found to have a microphase separated structure ${ }^{15}$ with the domain size ranging from several ten to several hundred nanometers, as shown in Figure 2.

\section{Biocompatibility of PMPC-b-PDMS}

It is generally accepted that the plasma protein adsorption, which is the initial event in blood-material interaction, will influence the subsequent platelet adhesion and activation. Therefore, the interaction between PMPC- $b$-PDMS and the serum proteins such as Alb, Glo, and Fib was studied to obtain basic information for biomedical applications, by using the glass beads $\operatorname{method}^{13}$ : at $\mathrm{pH} 5.6, \mathrm{pH} 6.2$, and $\mathrm{pH} 5.6$ for $\mathrm{Alb}$, Glo, and Fib, respectively. These $\mathrm{pH}$ values are close to the respective isoelectric points of the proteins.

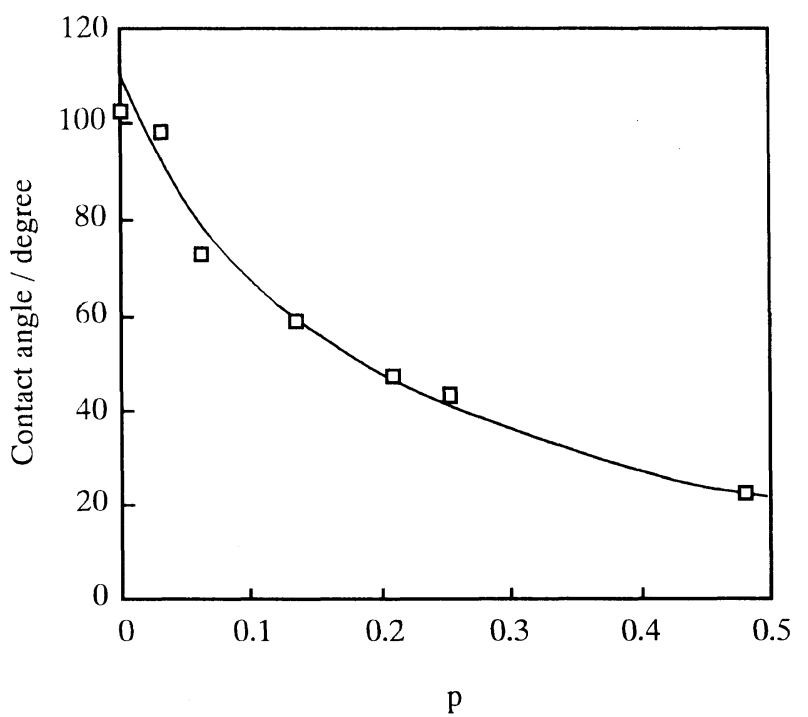

Figure 1. Effect of the molar ratio of MPC segment $(p)$ in PMPC- $b$-PDMS on the contact angle of water.

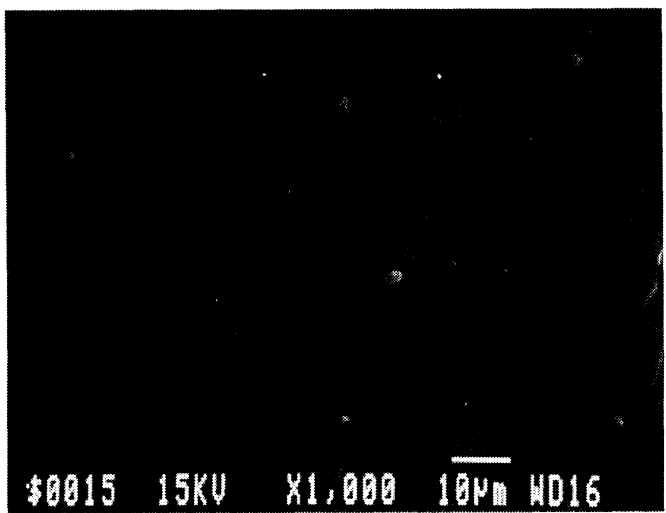

PDMS-b-PMPC-V
The amount of adsorption of proteins decreased with increasing $p$-value, as shown in Figure 3 . It is noteworthy that PMPC- $b$-PDMS effectively suppresses the adsorption of Fib, which is recognized as an important blood coagulation factor. ${ }^{15}$ Blood compatibility was

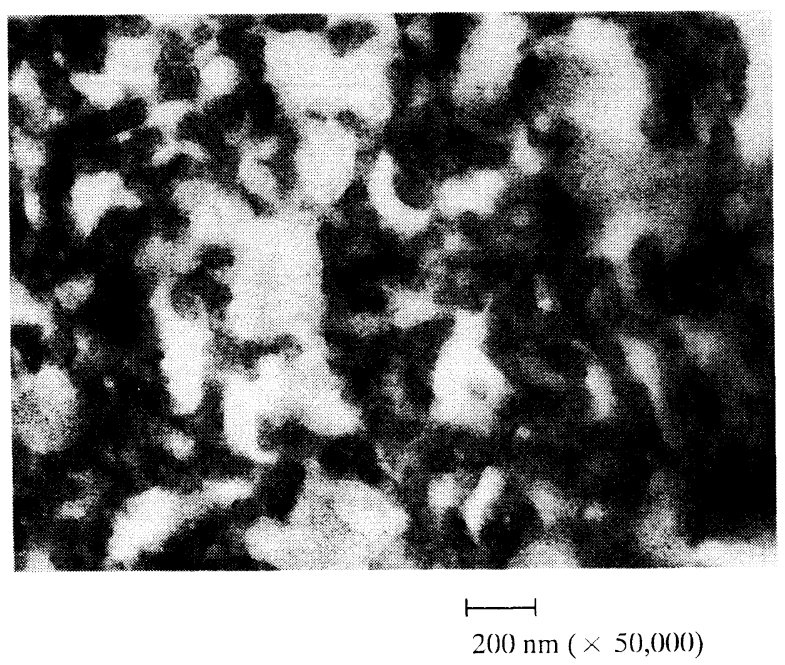

Figure 2. TEM micrograph of PMPC- $b$-PDMS-V.

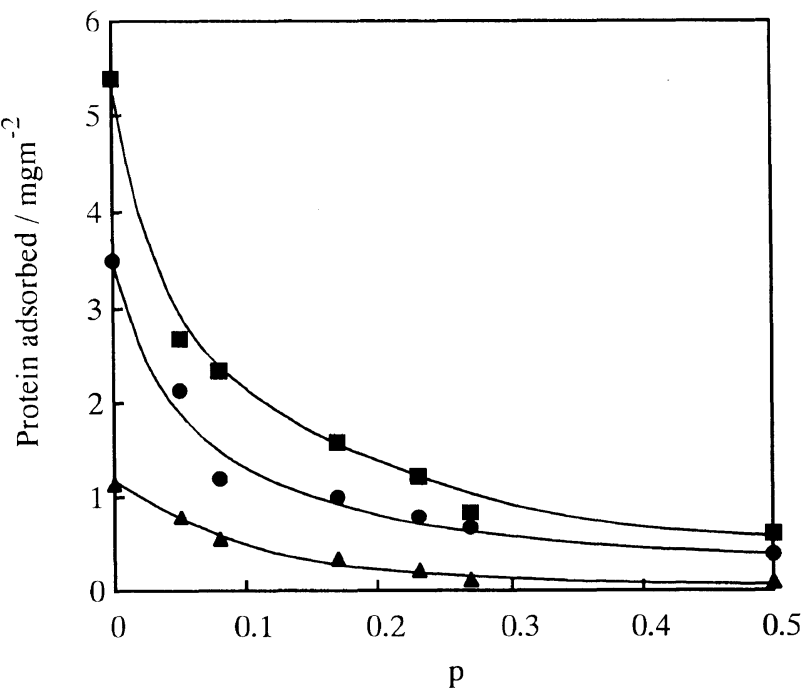

Figure 3. Adsorption of protein on PMPC- $b$-PDMS; $[\text { Protein }]_{0}=50$ $\mathrm{mgL}^{-1}, \mathrm{pH} 5.6$ for Alb, $\mathrm{pH} 6.2$ for Glo, $\mathrm{pH} 6.0$ for Fib, ionic strength $0,01,2$ h. $\mathbf{\Delta}, \mathrm{Alb} ; \boldsymbol{\bullet}, \mathrm{Glo} ; \mathbf{\square}$, Fib.

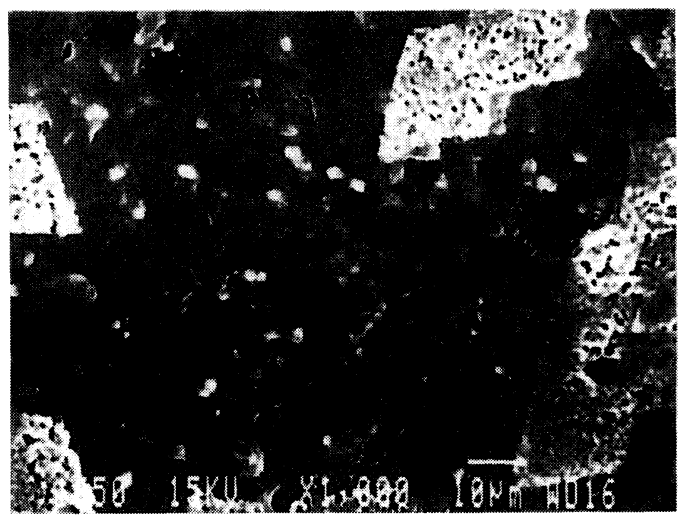

silicone

Figure 4. SEM micrographs of PDMS- $b$-PMPC-V and silicone after contact with PRP for $180 \mathrm{~min}$. 
also evaluated by the adhesion of human platelets. Figure 4 exhibits the SEM micrograph of PMPC- $b$-PDMS-V after contact with PRP for $180 \mathrm{~min}$, together with the case of silicone rubber as a control. No activation of platelets occurs on the PMPC- $b$-PDMS-V, whereas platelets aggregate and deform on silicone rubber. In conclusion, PDMS- $b$-PMPC is expected to be a new material having both a hydrogel structure and a microphase-separation structure for biomedical uses.

Acknowledgment. This study was partly supported by a Grant-in-Aid for Scientific Research (No. 0980869) from the Ministry of Education, Science, Sports and Culture of Japan.

\section{REFERENCES}

1. A. Kishida, T. Furuzono, T. Ohshige, I. Maruyama, T. Matsumoto, H. Itoh, M. Murakami, and M. Akashi, Angew. Makromol. Chem., 220, 89 (1994).

2. T. Furuzono, E. Yashima, A. Kishida, I. Maruyama, T. Matsumoto, and M. Akashi, J. Biomater. Sci., Polym. Ed., 5, 89 (1993).

3. Y. Tezuka, A. Fukushima, S. Matsui, and K. Imai, J. Colloid Interface Sci., 114, 16 (1986).
4. E. Nyilas, US Patent 356352 (1971).

5. K. Sugiyama, K. Kato, M. Kido, K. Shiraishi, K. Okada, and O. Matsuo, Macromol. Chem. Phys., 199, 1201 (1998).

6. K. Ishihara, T. Ueda, and N. Nakabayashi, Polym. J., 22, 355 (1991).

7. K. Ishihara, H. Oshida, Y. Endo, T. Ueda, A. Watanabe, and N. Nakabayashi, J. Biomed. Mater. Res., 26, 1543 (1992).

8. K. Sugiyama, K. Oga, and H. Aoki, Macromol. Chem. Phys., 196, 1907 (1995).

9. K. Sugiyama and H. Aoki, Polym. J., 26, 561 (1994).

10. K. Ishihara, H. Miyazaki, T. Kurosaki, and N. Nakabayashi, $J$. Biomed. Mater. Res., 29, 181 (1995).

11. H. Inoue, A. Ueda, and S. Nagai, J. Polym. Sci., Part A, Polym. Chem., 26, 1077 (1988).

12. K. Sugiyama, N. Tanigawa, and K. Shiraishi, Nippon Kagaku Kaishi, 551 (1998).

13. K. Sugiyama, S. Akita, Y. Tomoi, K. Hanaki, K. Shiraishi, and K. Ueda, Nippon Kagaku Kaishi, 139 (1997).

14. O. H. Lowry, N. J. Rosebrough, A. L. Farr, and R. J. Randall, J. Biol. Chem., 193, 265 (1951).

15. K. Senshu, S. Yamashita, M. Ito, A. Hirao, and S. Nakahama, Langmuir, 11, 2293 (1995).

16. T. Okano, S. Nishiyama, I. Shinohara, T. Akaike, Y. Sakurai, K. Kataoka, and T. Tsuruta, J. Biomed. Mater. Res., 25, 1397 (1991).

17. A. Takahara, K. Korehisa, K. Takahashi, and T. Kajiyama, Kobunshi Ronbunshu, 49, 275 (1992) 